\title{
O PAPA É POP: A ABORDAGEM MÍTICA DE FRANCISCO NA MULTIMÍDIA, UMA ANÁLISE POR MEIO DOS ESTUDOS DO IMAGINÁRIO E DO MITO
}

\author{
Cláudia Nandi Formentin ${ }^{1}$ \\ Marília Köenig ${ }^{2}$
}

\section{INTRODUÇÃO}

O presente trabalho pretende abordar, por meio dos estudos do imaginário e do mito, o fenômeno midiático ocorrido a partir da posse do cardeal argentino Jorge Mario Bergoglio (com 76 anos na época) ao maior cargo da Igreja Católica em 13 de março de 2013. Ele é o primeiro latino americano e o primeiro jesuíta a assumir o cargo. Seu antecessor, papa Bento XVI, renunciou alegando não ter condições de liderar a igreja em meio a várias crises enfrentadas em seu papado. Segundo o Portal G1 (2013) o novo pontificado se inicia "com a função de manter a unidade de uma igreja que, nas palavras de seu próprio antecessor, está dividida internamente e imersa em crises".

Já no início o Papa Francisco fez escolhas que privilegiaram a simplicidade, como a de se manter na casa em que ficou hospedado durante o conclave, ou a escolha de seu nome, uma homenagem a São Francisco de Assis conhecido pela vida simples, o que criou um clima de aproximação com a comunidade católica. Eventos de semelhante importância se repetiram até a presente data, todas noticiadas pela grande imprensa.

É nesse contexto que se apresenta as questões problemas do artigo aqui apresentado: os textos publicados na imprensa constituem uma narrativa mítica? $\mathrm{O}$ que, por meio dos estudos do imaginário, a abordagem da mídia a Francisco (o portal G1, mais especificamente), contraria e/ ou reforça os padrões católicos em torno da figura do sumo pontífice?

Para responder a tais perguntas, estabeleceu-se como objetivo geral analisar se os textos cotejados da imprensa constituem-se em uma narrativa mítica

\footnotetext{
${ }^{1}$ Faculdade Satc (Criciúma - SC), Faculdade Senac - SC e Unisul. E-mail: formentinnandi.claudia@gmail.com

${ }^{2}$ Faculdade Satc (Criciúma - SC), Faculdade Senac - SC. E-mail: maiam 78@hotmail.com
} 
no imaginário coletivo e como objetivos específicos: identificar características que diferenciam o Papa Francisco de outros pontífices, seus predecessores; identificar nos temas abordados pelas matérias possíveis, necessidades da sociedade contemporânea em termos do religar (re-ligare), base do Cristianismo e nesta abordagem, do Catolicismo.

Para realizar tal análise de textos midiáticos, selecionados especialmente de suporte digital, foram utilizados como escopos teóricos Legros et al (2007), Maffesoli $(2005,2007,2010)$ e Barthes (2003).

\section{IMAGINÁRIO NA MULTIMÍDIA: O PAPA É POP}

Neste item, destaca-se o conceito de imaginário e suas implicações, em especial mediante o objeto ora estudado. É abordada, ainda, a ideia de nação expressada por intermédio da obra de Lima Barreto, em especial nas crônicas da coletânea aqui estudadas, Vida urbana.

Para Durand (2002), o imaginário consiste no conjunto e nas relações entre as imagens, as quais compõem o capital "pensado do homo sapiens" (p. 37), sendo, "o denominador onde se encaixam todos os procedimentos do pensamento humano". Para o autor, do qual Maffesoli foi discípulo, o imaginário corresponde ao trajeto antropológico do indivíduo e as influências que este sofre da sociedade e a ela causa. Nesse trajeto, "a representação do objeto se deixa assimilar e modelar pelos imperativos pulsionais do sujeito [...] e no qual, reciprocamente, como magistralmente provou Piaget, as representações subjetivas se explicam pelas 'acomodações anteriores do sujeito ao meio objetivo'” (DURAND, 2002, p. 41).

A manifestação do imaginário é a cultura. Esta é a materialidade do imaginário. Ele, contudo, não se restringe às manifestações culturais. É a atmosfera, a aura intangível que está por trás de toda materialidade da cultura.

A cultura é um conjunto de elementos e de fenômenos passíveis de descrição. O imaginário tem, além disso, algo de imponderável. É o estado de espírito que caracteriza um povo. Não se trata de algo simplesmente racional, sociológico ou psicológico, pois carrega também algo de imponderável, um certo mistério da criação ou da transfiguração (SILVA, 2001, p. 76). 
E sendo a comunicação social uma das manifestações da cultura de uma comunidade, é passível de ser estudada pelas vias do imaginário. Este, para Maffesoli, só existe na coletividade. Para tanto, refere-se sempre ao vínculo, ao estar-junto e, justamente por essa razão, é cimento social e não pode ser individualizado. Maffesoli reforça essa questão ao falar da pós-modernidade ou contemporaneidade, sendo esta, para o estudioso, o momento de religação (religare), de reunião, do estar-junto e da expressão, via arte e comunicação, da essencial socialidade humana.

Talvez aqui o papel desempenhado pelo Papa Francisco junto aos fiéis católicos e mesmo a pessoas não religiosas represente, via abordagem midiática, essa reconexão com o divino, o transcendente, justamente por sua humanidade.

Silva (2001) enfatiza que resta, segundo Maffesoli, questionar a ideia que se tem de retorno. Tal ideia está sujeita ao mesmo equívoco que outrora a noção de imaginário esteve. Nela, de acordo com o teórico francês,

há uma acepção de reversão, de regressão, de engano. Penso que certos elementos colocados de lado pela razão retornam, não no sentido do idêntico ou da regressão, mas da ocupação de um novo lugar de destaque. Em outras palavras, nunca desapareceram. Estavam apenas em posição secundária. Ou latente. Há sempre algo de romântico no político, perspectiva de uma sociedade perfeitamente igualitária, etc. Creio que há, de fato, reaparecimento de uma sensibilidade romântica. Na ecologia, por exemplo, com a revalorização da natureza (SILVA, 2001, p. 78).

O reaparecimento dessa sensibilidade romântica descria por Silva podese vislumbrar nas abordagens sobre o papa Francisco ora analisadas. Desse modo, remontam a uma volta aos valores elementares da convivência humana, do estarjunto.

Nesse contexto, para Maffesoli (in SILVA, 2001), diversas questões que estavam latentes na modernidade retornam no sentido de vibração, de um novo humanismo, de uma nova ideia que remonta ao passado.

O tal religare, tão presente na gênese da Sociologia do imaginário (LEGROS et al, 2007), pode ser vislumbrado nesse contexto. Criticar as desigualdades sociais trazidas pelo rápido e amplo processo de urbanização (ou modernização, uma vez ser a cidade o signo máximo da modernidade) foi o modo de Francisco, por meio da simplicidade e interação manifesta em suas atitudes, descritas nas matérias jornalísticas aqui expostas, mitificar-se, de algum modo. 
Assim,

$\mathrm{Na}$ maior parte do tempo, o imaginário dito individual reflete, no plano sexual, musical, artístico, esportivo, o imaginário de um grupo. O imaginário é determinado pela idéia (sic) de fazer parte de algo. Partilha-se uma filosofia de vida, uma linguagem, uma atmosfera, uma idéia (sic.) de mundo, uma visão das coisas, na encruzilhada do racional e do não-racional (MAFFESOLI in SILVA, 2001, p. 80).

Para Legros (et al, 2007), a vida humana é constantemente submetida aos impulsos imaginários, às imagens "encarnadas" nas artes (pictóricas, cinematográficas, etc.) e nas construções mentais individuais e coletivas. Há aqui, portanto, uma noção mais tangível, a nosso ver, de imaginário. É um fenômeno coletivo, social, histórico; uma sociologia destituída do imaginário é mutilada. A tradição iniciada por Jung, Bachelard, Eliade, Durand (o imaginário como produto do pensamento mítico) se contrapõe à antiga noção de imaginário como algo irreal (tradição filosófica ocidental).

Há, segundo os autores, três significados ao imaginário social definidos por Stronneau (1993):

- dimensão mítica da existência social - mitos de uma época, de uma nação, etc., e onde, na visão das pesquisadoras, a narrativa em torno do papa se insere;

- imaginação de outra sociedade - ideologias revolucionárias e utopias;

- imaginário mais moderno e cotidiano (recente) - distrações populares.

Para Pareto, conforme Legros (et al, 2007), a Sociologia deve deter preocupação com as ações não-lógicas (rituais ou simbólicas) da vida social, tais como a veneração religiosa, o fervor patriótico e a efervescência em torno de um emblema (uma flâmula, talvez) sagrado, os quais acarretam tais condições. Para o sociólogo, os homens dão uma cobertura racional a atos que, na realidade, são determinados por desejos e sentimentos.

$\mathrm{Na}$ abordagem via Jornalismo, tido como um discurso referente à realidade e por natureza, objetivo, percebemos que o entendimento acerca dos atos de Francisco ultrapassa essa objetividade por uma sensibilidade consensual (cumsensualis, nos termos de Maffesoli (2007) entre católicos e até mesmo não-católicos. 
Destaca, por fim, que é preciso, portanto, tornar perceptível o intangível. A cultura e suas materialidades (as abordagens jornalísticas, inclusive), aqui, têm um papel preponderante. Tornam tangível o imaginário, o qual é impossível tocar ou restringir.

O imaginário é, pois, uma rede intangível e movediça de valores, sentimentos e sensações compartilhadas concreta e virtualmente (SILVA, 2006). No imaginário essas visualizações são encontradas. Tais questões que, embora tácitas, estão presentes na cultura de uma sociedade, sendo absorvidas pelo vivido (MAFFESOLI, 2004). Portanto, o mito do herói, do salvador, faz-se presente nas abordagens jornalísticas acerca do Papa Francisco.

A imaginação, aqui, firma-se no imaginário coletivo daquele momento histórico-cultural, sendo o imaginário, nas palavras do teórico francês, uma aura, a qual não se pode ser vista, mas sentida. Uma atmosfera. Por isso Silva (2006) afirma ser o imaginário um reservatório/ motor. É reservatório por agregar imagens, experiências, sentimentos e leituras da vida. $\mathrm{O}$ imaginário emana do real, estruturase como ideal e retorna ao real como um elemento propulsor (SILVA, 2006).

A comunicação social, em especial o Jornalismo, se constitui como uma materialidade e seus dispositivos compõem tecnologias do imaginário, termo de Silva (2006). Cabe ao pesquisador dessas tecnologias fazer a narrativa do vivido, "como um etnógrafo das emoções e das práticas, a exemplo de um repórter de todas as paixões e acontecimentos do cotidiano", pois "o imaginário é um mundo em movimento" (SILVA, 2006, p. 79).

E é justamente essa relação indissociável entre o imaginário (atmosfera subjacente às relações, fluida e intangível) com o Jornalismo (objetivo, tangível e contextualizado, portanto), que pode ser percebida aqui.

\section{MITO E IMAGINÁRIO COLETIVO NA MULTIMÍDIA}

A existência humana na Terra é marcada pela necessidade de explicar fenômenos que intrigavam os homens. Nesse sentido os mitos não são uma invenção moderna, remontam as civilizações que ainda não tinham na ciência uma área desenvolvida em sua cultura. No entanto, não é possível afirmar que os mitos 
foram esquecidos nas civilizações mais antigas. Foi a transformação no modo de tratar sobre o tema que mudou e permitiu que o mito chegasse a atualidade.

Os recursos da imagem e da fantasia dos mitos abrem para a consciência, o acesso ao inconsciente coletivo que nada mais é do que aquilo que herdamos das vivências das gerações passadas. Ninguém ignora que a mitologia é um tecido fantástico de fantasias que, algumas vezes, parecem verdade, outras, soam como absurdas, sem lógica. Assim, o inconsciente coletivo expressaria a identidade de todos os homens independente da época e do lugar em que viveram. O inconsciente coletivo não se manifesta de forma conceitual ou verbal, ele se faz através de símbolos (BRUNEL, 1998).

Em quase todas as narrativas mitológicas, a presença do herói é marcante. Nestas situações, o herói consegue se controlar mesmo em momentos adversos, passa por obstáculos difíceis ou quase instransponíveis para os mortais e realiza façanhas que trazem o bem para a coletividade. Há ainda a figura do guerreiro que, de certa forma, se mistura com a do herói, que tem coragem e consegue vencer inimigos perigosos, trazendo orgulho para seu povo e mudando a vida deste.

É possível observarmos, ao longo da história da humanidade, que os povos, em geral, têm uma certa necessidade de criar mitos, com finalidade de explicar contradições, paradoxos, dúvidas, inquietações e até mesmo para justificar conceitos morais vigentes, em determinada época. O mito é o lugar onde o objeto é criado partindo de uma pergunta e de sua resposta, a partir de sua mais profunda natureza um objeto se torna criação.

Os mitos também procuram mostrar os exemplos de conduta, positivos ou negativos, que devem ser ou não seguidos pela sociedade. Nesse sentido Martinez (2008) aponta para o que Joseph Campbell chama de função pedagógica do mito. Tal definição "permite ao leitor que imerge na história de um indivíduo relacioná-la à própria trajetória, tirando ensinamentos que pode utilizar em sua própria existência" (MARTINEZ, 2008, p. 38-39).

Barthes (2003, p. 200), a seu turno, afirma que o mito não pode "ser um objeto, um conceito ou uma ideia: ele é um modo de significação, uma forma". O autor afirma isto, pois, para ele, o mito é uma fala, porém, não qualquer fala. Esta fala, à qual se refere o filósofo francês, é uma mensagem, portanto, não necessariamente oral; "pode ser formada por escritas ou representações: o discurso 
escrito, assim como a fotografia, o cinema, a reportagem, o esporte, os espetáculos, a publicidade, tudo isso pode servir de apoio à fala mítica" (BARTHES, 2003, p. 200).

E já que o mito é uma fala, afirma Barthes (2003, p. 199) "tudo pode constituir um mito, desde que seja suscetível de ser julgado por um discurso". Segundo o autor nada pode proteger-se do mito, e é a língua que oferece fraca resistência a ele, é ela, a linguagem, que mais frequentemente é roubada por ele. Poder-se-ia dizer, então, que o mito é tudo aquilo que escapa à linguagem discursiva que foge da lógica e da razão. São várias vozes sociais que acabam se encontrando nos mitos: questões familiares e de relacionamento, religião, dentre outros se encontram em torno de um mito.

Nesse sentido, pode-se perceber que os enunciados não apenas refletem a expressão de algo que já existe em seu exterior e pronto. Cria-se algo novo e singular, que se relaciona com algum valor (verdade, bondade, beleza, dentre outros), mas que não foi criada do nada. Ela já parte de algo existente na sociedade. Até porque a partir do momento em que não esperamos nada da palavra além do que já sabemos que ela pode nos oferecer, não há mais diálogo e a palavra se "coisifica".

Nos dias de hoje, dominados pela comunicação de massa, esse papel cabe ao artista, como se o papel do artista, na sociedade atual, fosse a mitificação do ambiente e do mundo. Os veículos de comunicação de massa criam mundos mito-simbólicos em que os seres humanos possam projetar os seus sonhos, medos e fantasias. O mito molda a vida das pessoas mesmo quando elas não se apercebem disto. No centro de um grande número de mitologias existe um símbolo, uma imagem arquetípica que traça o caminho da mitologia que, por sua vez, molda a vida das pessoas que entram em contato com ela.

Quando se pergunta onde os mitos estariam hoje, Bricout responde que eles estão em todos os lugares, mas, ao mesmo tempo, são clandestinos. "Está aí e, no entanto, ninguém o reconhece" (BRICOUT, 2003, p. 14). A autora (2003, p. 15) ainda comenta que durante a Antiguidade o mito, em principio, "era um espetáculo ritual, mimado, ritmado, cantado, contado, figurado, constituindo-se na suprema referência para as leis religiosas da tribo, do clã e da cidade, hoje ele se oferece a nós muito mais como um teatro de sombra". 
O mito contemporâneo, no pensamento de Barthes (1977, p. 11), "é desconstituído: ele não se enuncia mais em grandes narrativas constituídas, mas somente em 'discurso'; é quando muito uma fraseologia, um corpus de frase (de estereótipos); o mito desaparece, mas permanece, tanto mais insidioso, o mítico". Nesse sentido, os mitos não param de aparecer e, por isso mesmo, a cada dia surge um novo modelo a ser seguido. Como se pode vislumbrar, no entendimento das pesquisadoras, na abordagem multimidiática ao Papa Francisco, conforme se intenta destacar na análise que segue.

\section{O PAPA É POP: ANÁLISE DE DUAS ABORDAGEM DE FRANCISCO NA MULTIMÍDIA}

A fim de realizar um recorte alusivo à questão que ora são abordadas, as pesquisadoras escolheram duas matérias relativas ao Papa Francisco publicadas pelo portal de notícias G1, das Organizações Globo. Segue a primeira matéria para análise, a qual destaca o seguinte conteúdo: "O Papa Francisco decidiu ficar morando, "até segunda ordem" na Casa Santa Marta, no Vaticano, instalações simples e modernas onde se hospedou juntamente com os outros cardeais para o conclave que o elegeu pontífice em 13 de março".

A afirmação foi publicada pelo portal de notícias $G 1$ no dia 26 de março de 2013. Na matéria intitulada 'Papa Francisco decide continuar morando na Casa Santa Marta' há a explicação de quais foram os motivos que levaram o pontífice recém-eleito a tomar tal decisão. Segundo as fontes apresentadas pelo veículo Francisco gosta da "atmosfera da residência onde ele vive junto com outros clérigos" e continua afirmando que "o papa reza uma missa na capela local todas as manhãs e convida os trabalhadores do Vaticano e outros convidados a participar". Além disso, "Francisco estabeleceu um tom mais austero para o papado em relação a seu antecessor Bento XVI, que ganhou uma reputação de adotar costumes suntuosos".

Nessa matéria já é possível identificar questões que contribuem na construção do imaginário, como, por exemplo a ideia relacionada a coletividade.ao apresentar um pontífice que não só participa de uma coletividade mas gosta deste 
estar-junto. Além disso, a matéria indica mudança de comportamento do pontífice eleito e de seu antecessor. Vê-se nesse sentido uma aproximação com as pessoas que não fazem parte do clero mas tem no papa uma figura que se torna um exemplo a ser seguido.

Como foi visto no referencial teórico deste trabalho, é por essa razão que Silva (2006) afirma ser o imaginário um reservatório/ motor. É reservatório por agregar imagens, experiências, sentimentos e leituras da vida. O imaginário emana do real, estrutura-se como ideal e retorna ao real como um elemento propulsor (SILVA, 2006). Daí a surpresa tanto do clero quanto (e sobretudo) da comunidade católica ao perceber que as atitudes de Francisco destoam sobremaneira da de seu antecessor, motivando muitas pessoas a, inclusive, voltar seus olhos à igreja novamente, tendo em vista as atitudes agregadoras e destituídas de preconceito que o pontífice tem continuamente.

O Jornalismo, tido como discurso de verdade em direta relação com o referente, ou seja, o real, se constitui como uma materialidade e seus dispositivos compõem tecnologias do imaginário, termo de Silva (2006). Cabe ao pesquisador dessas tecnologias fazer a narrativa do vivido, reportando os acontecimentos do cotidiano considerando o imaginário como um mundo que está, continuamente, em movimento (SILVA, 2006).

A próxima abordagem analisada Papa oferece hospedagem a indigente que deu à luz na rua: matéria destaca situação em que o bebê nasceu e o lugar onde estão mãe e filho (uma instituição da Santa Sé), em 20/01/2016.

$\mathrm{Na}$ referida matéria publicada pelo G1, não há imagens, apenas texto. Destaca-se que

A indigente deu à luz na rua às $2 \mathrm{~h} 30$ de quarta-feira, sob uma temperatura de menos um grau e com a ajuda de uma policial que patrulhava a região. $\mathrm{A}$ comunidade católica de São Egídio, comprometida na assistência de pessoas sem teto, considera que o parto nessas condições é um "sinal de alarme" da crise econômica na Itália.

Nesta terça-feira, um imigrante romeno sem teto morreu em Roma, provavelmente de frio. Muitos indigentes e pessoas sem casa vivem nas proximidades do Vaticano, graças ao aumento da assistência oferecida por Francisco desde a sua eleição há quase três anos"

Pelos caminhos do imaginário, em diversas instâncias, aproxima-se, pelo caráter progressista, Francisco de João Paulo II, sendo aquele, porém, mais simples 
e acessível ao povo. Faz-se, no entanto, a forte contraposição do atual papa a Bento 16, seu predecessor, haja vista ser este homem de hábitos suntuosos.

Francisco remonta ao mito do herói que acolhe os pobres, mas recusa luxos do Vaticano (reforço da bondade esperada do papa, e contraponto pela simplicidade franciscana. No entendimento de Barthes (2003, p. 200), "a narrativa mítica pode ser formada por escritas ou representações". Nesse contexto, o discurso escrito (nesse caso as matérias publicadas no G1 ora expostas), assim como a fotografia, o cinema, a reportagem (mais uma referência ao objeto de análise deste trabalho), o esporte, os espetáculos, a publicidade, podem servir de sustentáculo à fala mítica.

Talvez aqui o papel desempenhado pelo Papa Francisco junto aos fiéis católicos e mesmo a pessoas não religiosas represente, via abordagem midiática, essa religação com o divino, o transcendente, justamente por sua humanidade.

Dentre os diversos processos interacionais existentes, há a comunicação social. Pode-se dizer que as abordagens do G1, não obstante pretensamente objetivas por se tratar de textos jornalísticos, quando se referem aos atos do atual papa, são permeadas por "uma vibração que supera o argumento e instaura uma sensibilidade comum" (SILVA, 2001, p. 77).

\section{CONSIDERAÇÕES FINAIS}

A partir desse olhar em torno das questões do mito e do imaginário, percebeu-se que os materiais estudados se constituem em uma narrativa mítica por apontarem para necessidades atemporais da sociedade em eleger mitos. Reforçam, ainda, características diferenciais do papa (abertura, quebra de paradigmas e pompas do Vaticano e sua simplicidade/ informalidade).

Os textos publicados na imprensa sobre ele constituem uma narrativa mítica, haja vista a presença constante e subjacente, nessas matérias, do arquétipo do herói. Por meio dos estudos do imaginário, a abordagem da mídia a Francisco (o portal G1, mais especificamente), contraria os padrões católicos em torno da figura do sumo pontífice, contudo, reforçam uma sensibilidade comum em torno da figura do papa "do povo", remetendo, inclusive, a uma relação interdiscursiva a São 
Francisco, moço italiano rico que abandona os luxos inerente à sua condição de fidalgo em favor dos menos favorecidos.

Nesse sentido, as matérias sobre Francisco dão conta da existência de um papa "humano" e mais acessível aos fiéis, justamente por dispensar a pompa conferida a alguém de sua posição. Um papa mais político, no sentido de relacionarse de modo mais próximo com os fiéis e com a mídia, de modo mais amplo, de quem promove o bem "sem olhar a quem", seja esse sujeito uma mãe indigente, uma mãe solteira ou os trabalhadores do Vaticano, com o papa faz questão de fazer suas refeições continuamente.

Acerca disso, Silva (2001, p. 78), vai pontuar haver "sempre algo de romântico no político, perspectiva de uma sociedade perfeitamente igualitária, etc. Creio que há, de fato, reaparecimento de uma sensibilidade romântica" (...). Sentimento este que confere às abordagens do G1 ora analisadas uma aura mítica, na qual o papa pode ser entendido como uma espécie de herói contemporâneo.

Indicam, ainda, que Francisco enfrenta dificuldades (correspondendo ao mito/ arquétipo do herói) junto a setores mais conservadores da Santa Sé, e serve de exemplo a ser seguido pelos católicos, conforme se espera de um papa (no imaginário coletivo em torno da figura do sumo pontífice), não obstante seu perfil tido como inovador.

\section{REFERÊNCIAS}

BARTHES, Roland. Mitologias. Rio de Janeiro: Difel, 2003.

BARTHES, Roland. Mudar o próprio objeto. In: tradução de NASCIMENTO, Carlos Arthur R. do. Atualidade do Mito. São Paulo: Duas Cidades, 1977.

BRICOUT, Bernadete. O olhar de Orfeu: os mitos literários do Ocidente. São Paulo: Companhia das Letras, 2003.

G1. Papa Francisco decide continuar morando na Casa Santa Marta. 26 mar. 2013.

Disponível em: < http://g1.globo.com/mundo/noticia/2013/03/papa-francisco-decide-continuarmorando-na-casa-santa-marta.html>. Acesso em: 12 maio 2016.

G1. Papa oferece hospedagem a indigente que deu à luz na rua. 20 jan. 2016. Disponível em: $<$ 
http://g1.globo.com/mundo/noticia/2016/01/papa-oferece-hospedagem-indigenteque-deu-luz-na-rua.html>. Acesso em: 12 maio 2016.

MAFFESOLI, Michel. No fundo das aparências. Tradução de Bertha Halpern Gurovitz. $3^{\underline{a}}$ edição. Editora Vozes, Petrópolis 2005.

O conhecimento comum. Tradução de Aluízio R. Trinta. Coleção Imaginário Cotidiano. Porto Alegre: Sulina, 2010;

O ritmo da vida: variações sobre o imaginário pós-moderno. Tradução de Clóvis Marques. Rio de Janeiro: Record, 2007.

MARTINEZ, Monica. Jornada do Herói: a estrutura narrativa mítica na construção de história de vida em jornalismo. São Paulo: Annablume, 2008.

ROMANINI, Vinicius. Mitos: por que precisamos deles? Terra. 144 ed.. Peixes. Abr. 2004.

SILVA, Juremir Machado da.Tecnologias do imaginário. Porto Alegre: Sulina, 2006.

. O imaginário é uma realidade. Entrevista de M. Maffesoli. In: Revista FAMECOS - no 15 (quadrimestral). Porto Alegre, agosto de 2001. 